\title{
|||||||||||||||||||||||||||||||||||||||||||||||||||||||||||||||||||.
}

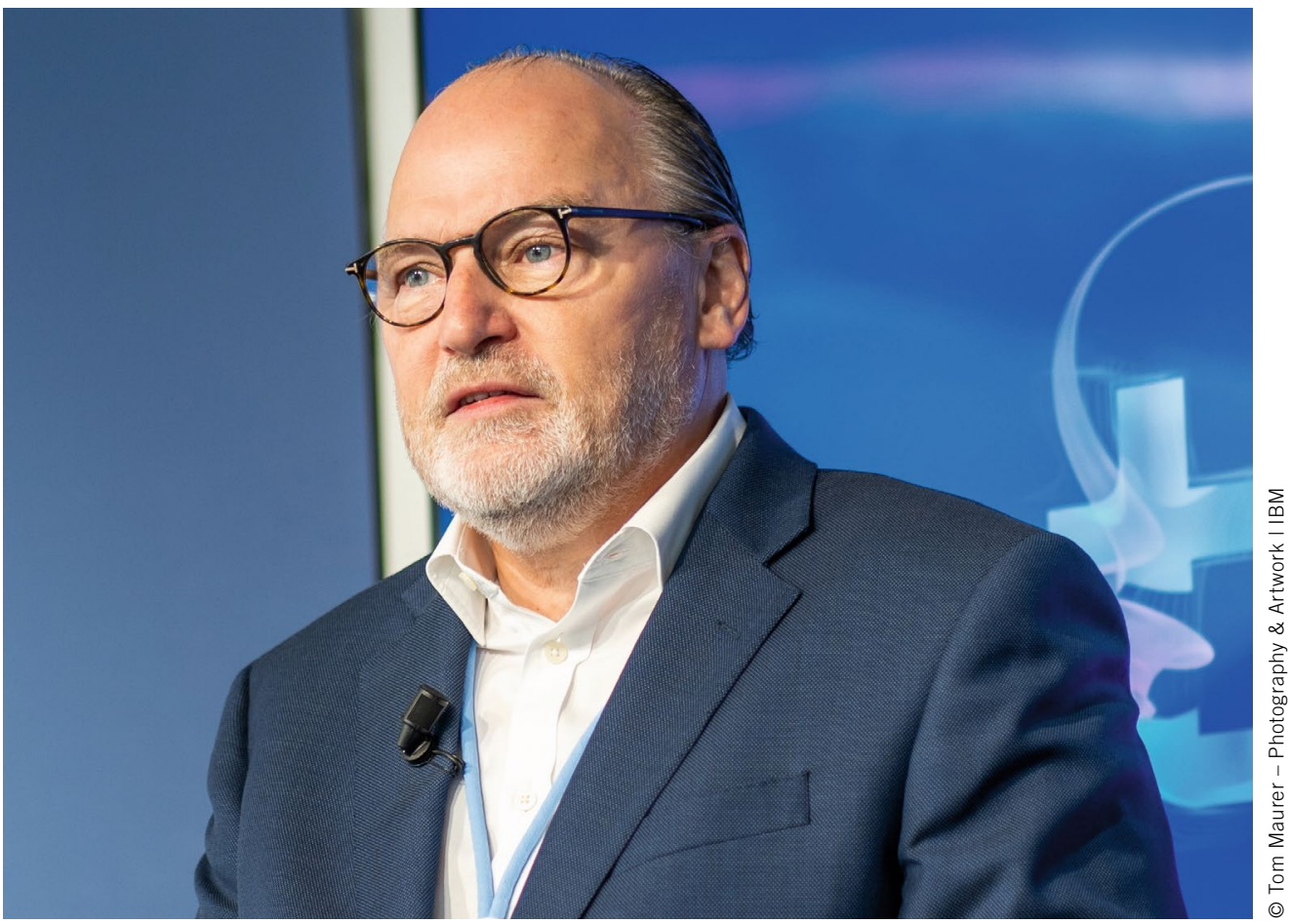

Dirk Wollschläger General Manager Global Automotive Industry bei IBM Deutschland

\section{Mobilitätsstudie - Das bewegt München}

Die politische und gesellschaftliche Debatte um die Mobilitätswende nimmt Fahrt auf. Dies zeigt beispielsweise die Neuausrichtung der IAA zur Mobilitätsmesse, bei der neben (Elektro-) Autos auch andere Fortbewegungsmittel präsentiert wurden. Aber auch die anhaltenden Diskussionen um die Elektromobilität generell: ein Reizthema. Die Kritik reicht von nicht alltagstauglichen Ladezeiten bis hin zu Bedenken über die tatsächliche Nachhaltigkeit von E-Fahrzeugen.

Dies hat IBM veranlasst, gemeinsam mit dem Marktforscher Morning Consult die Endkunden nach ihren Einstellungen zu nachhaltiger Mobilität, E-Autos und ihrem eigenen $\mathrm{CO}_{2}$-Fußabdruck zu befragen. Insgesamt äußerten sich 1000 erwachsene Münchner und Münchnerinnen in einer repräsentativen Umfrage. Das Bewusstsein, nachhaltig zu handeln, ist groß: $79 \%$ der Befragten gaben an, dass ihnen ihr individueller $\mathrm{CO}_{2}$-Fußabdruck „wichtig“ (43\%) und sogar „sehr wichtig“ (36 \%) ist. Unerwartet achtet die ältere Generation stärker als die jüngere auf ihren persönlichen Abdruck: 51 \% der Befragten ab 65 Jahren sind ihr $\mathrm{CO}_{2}$-Abdruck „sehr wichtig“. Bei den 18- bis 34Jährigen sind es nur $30 \%$.

Die eigene $\mathrm{CO}_{2}$-Bilanz ist bei der Wahl des täglichen Transportmittels nur noch für etwas mehr als die Hälfte (56 \%) entscheidend. Bequemlichkeit und Geschwindigkeit siegen. Dennoch berücksichtigen Befragte ab 65 Jahren doppelt so häufig Nachhaltigkeitsaspekte bei der Wahl des Transportmittels - im Vergleich zur Altersgruppe der 18- bis 34-Jährigen. Und wie stehen die Befragten zur E-Mobilität? Insgesamt betrachten 58 \% E-Fahrzeuge als umweltfreundlich und nachhaltig. Die jüngeren Jahrgänge zeigen im Vergleich zu den älteren mehr Begeisterung: Während $20 \%$ der 18- bis 34-Jährigen „voll und ganz“ zustimmen, sind es bei den über 65-Jährigen lediglich $6 \%$. Bei den 35- bis 44-Jährigen sind es $16 \%$, bei den 45- bis 64-Jährigen $10 \%$. Mit steigendem Alter der Befragten nimmt die starke Zustimmung für elektrische Fahrzeuge also deutlich $\mathrm{ab}$.

Wenige Leute besitzen bereits ein E-Fahrzeug - nur $7 \%$. Mehr als ein Drittel (39 \%) ziehen in den nächsten Jahren in Betracht, eines zu kaufen. Über die Hälfte der Befragten (55 \%) planen keine Anschaffung. Der wichtigste Grund, kein E-Auto zu kaufen, sind die Kosten: Für 36 \% sind die Fahrzeugkosten schlichtweg (noch) zu hoch. Weitere Gründe: Zweifel an der tatsächlichen Umweltverträglichkeit von elektrisch betriebenen Fahrzeugen (29\%), ethische Bedenken in Bezug auf die Batterielieferketten (29\%), begrenzte Batterielebensdauer (25\%) und begrenzte Verfügbarkeit von Ladestationen (23\%).

Diese Bedenken abzubauen, ist entscheidend beim Umstieg von Benzin- und Diesel-Pkw auf E-Fahrzeuge. Daher unterstützt IBM auch die Erforschung batteriebetriebener Alternativen für alle Bereiche bis hin zu intelligenten Energienetzen. Denn E-Autos sind ein Baustein für nachhaltigere Mobilität. 